\title{
MENingKatKan KeMAMPUAN KoMUNiKaSi Matematis dan SELF- Confidence SisWa MElalui Model PEMBelajaran CyCle 7E
}

\author{
ENHANCING Mathematical Communication SKILl AND SELF-ConfidenCE \\ STUdenTS THROUGH CyCLE 7E LEARNING MODEL
}

\author{
Teni Sritresna \\ Program Studi Pendidikan Matematika, STKIP Garut \\ Garut, Jawa Barat, Indonesia \\ tenisritresna@gmail.com
}

\begin{abstract}
Abstrak
Penelitian ini dilatarbelakangi oleh hasil penelitian-penelitian terdahulu yang menunjukkan masih rendahnya kemampuan komunikasi matematis dan self-confidence siswa dalam belajar matematika. Learning Cycle 7E merupakan salah satu model pembelajaran yang diharapkan dapat meningkatkan kemampuan komunikasi matematis dan self-confidence siswa. Tujuan dari penelitian ini untuk mengetahui peningkatan kemampuan komunikasi matematis dan selfconfidence siswa yang mendapatkan model pembelajaran learning cycle 7E dengan yang mendapatkan model pembelajaran konvensional. Penelitian ini merupakan penelitian kuasi eksperimen dengan populasi siswa di salah satu SMP di Kabupaten Garut. Pengambilan sampel dilakukan dengan menggunakan teknik purposive sampling. Instrumen yang digunakan dalam penelitian ini berupas tes kemampuan komunikasi matematis dan skala sikap self-confidence siswa. Hasil analisis data menunjukkan bahwa peningkatan kemampuan komunikasi matematis dan self-confidence siswa yang mendapatkan model pembelajaran learning cycle 7E lebih baik daripada siswa yang mendapatkan pembelajaran konvensional.

Kata Kunci: Komunikasi Matematis, Self-Confidence, Learning Cycle $7 E$.
\end{abstract}

\begin{abstract}
This research is motivated by the results of previous studies which indicates the low ability of mathematical communication and self-confidence of students in learning mathematics. Learning Cycle $7 E$ is one of the learning model that is expected to improve the ability of mathematical communication and self-confidence of students. The purpose of this study to determine the improvement of mathematical communication skills and self-confidence of students who get learning model of learning cycle $7 E$ with which get the conventional learning model. This research is a quasi-experiment research with student population in one of junior high school in Garut. Sampling is done by using purposive sampling technique. The instrument used in this study examined the ability of mathematical communication and the scale of student self-confidence attitude. The result of data analysis shows that the improvement of mathematical communication ability and self-confidence of students who get the learning model of learning cycle $7 E$ is better than students who get conventional learning.

Keyword: Mathematical Communication, Self-Confidence, Learning Cycle $7 E$.
\end{abstract}

\section{Pendahuluan}

Komunikasi merupakan bagian yang esensial dari matematika dan pendidikan matematika (Turmudi, 2008: 55). Oleh karena itu, agar tercapai keberhasilan dalam belajar matematika kemampuan komunikasi matematis merupakan salah satu kemampuan yang harus dikuasai oleh 
siswa. Greenes dan Schulman (Saragih, 2007) mengemukakan bahwa komunikasi matematis merupakan: (1) kekuatan sentral bagi siswa dalam merumuskan konsep dan strategi, (2) modal keberhasilan bagi siswa terhadap pendekatan dan penyelesaian dalam eksplorasi dan investigasi matematika, (3) wadah bagi siswa dalam berkomunikasi dengan temannya untuk memperoleh informasi, berbagi pikiran dan penemuan, curah pendapat, menilai dan mempertajam idea untuk meyakinkan yang lain. Sedangkan, Yeager, A dan Yeager, R. (Izzati dan Suryadi, 2008) mendefinisikan komunikasi matematis sebagai kemampuan untuk mengomunikasikan matematika baik secara lisan, visual, maupun dalam bentuk tertulis, dengan mengunakan kosa kata matematika yang tepat dan berbagai representasi yang sesuai, serta memperhatikan kaidah-kaidah matematika

Pugalee (2001) menyatakan melalui proses komunikasi matematis siswa akan terbiasa untuk memberikan argumen untuk setiap jawabannya serta memberikan tanggapan atas jawaban yang diberikan oleh orang lain, sehingga proses pembelajarannya akan menjadi bermakna. Kebermaknaan dalam proses belajar matematika akan berdampak positif bagi siswa, misalnya pengetahuan yang baru akan lebih lama diingat, memudahkan belajar untuk pengetahuan yang serupa dan jika pengetahuan tersebut terlupakan akan tetap meninggalkan efek dalam struktur kognitif siswa sehingga dapat segera dipanggil kembali (Sumarmo, 2013).

Sumarmo (2013: 453) menyatakan bahwa indikator kemampuan komunikasi matematis, meliputi (1) menyatakan situasi, gambar, diagram, atau benda nyata ke dalam bahasa, simbol, idea, atau model matematik; (2) menjelaskan ide, situassi, dan relasi matematika secara lisan dan tulisan; (3) mendengarkan, berdiskusi, dan menulis tentang matematika; (4) membaca dengan pemahaman suatu representasi matematika tertulis; (5) membuat konjektur, menyusun argumen, merumuskan definisi, dan generalisasi; (6) mengungkapkan kembali suatu uraian atau paragraf matematika dalam bahasa sendiri.

Selain komunikasi matematis sebagai salah satu aspek kognitif, untuk menunjang keberhasilan siswa belajar matematika juga diperlukan aspek afektif, salah satunya self-confidence (kepercayaan diri). Bandura (Sudrajat, 2008) mengatakan bahwa self-confidence adalah percaya terhadap kemampuan diri dalam menyatukan dan menggerakkan motivasi dan sumber daya yang dibutuhkan, dan memunculkannya dalam tindakan yang sesuai dengan apa yang harus diselesaikan atau sesuai dengan tuntutan tugas.

Menurut Hannula, Hanna dan Erkki (2004), kepercayaan siswa pada matematika dan pada diri mereka sebagai siswa yang belajar matematika akan memberikan peranan penting dalam pembelajaran dan kesuksesan mereka 
dalam matematika. Lazard, Morony dan Ping (2011) berpendapat berdasarkan hasil penelitiannya, menemukan bahwa selfconfidence merupakan ukuran non kognitif yang lebih baik untuk melihat gambaran prestasi siswa dibandingkan dengan ukuran non kognitif lainnya.

Lautser (Sutisna, 2010) menyatakan bahwa self-confidence merupakan suatu sikap atau perasaan yakin atas kemampuan diri, sehingga orang yang bersangkutan tidak perlu cemas dalam tindakan-tindakannya, dapat merasa bebas untuk melakukan hal-hal yang disukainya dan bertanggung jawab atas perbuatannya, hangat dan sopan dalam berinteraksi dengan orang lain, memiliki dorongan untuk berprestasi serta dapat mengenal kelebihan dan kekurangannya.

Fatimah (2006) menyebutkan ciri-ciri individu yang memiliki self-confidence proposional sebagai berikut.

1. Percaya akan kemampuan diri sendiri, sehingga tidak membutuhkan pujian, pengakuan, penerimaan, atau rasa hormat dari orang lain.

2. Tidak terdorong menunjukkan sikap konformis demi diterima orang lain atau kelompok.

3. Berani menerima dan menghadapi penolakan orang lain.

4. Memiliki kendali diri yang baik.

5. Memiliki internal locus of control (memandang keberhasilan/kegagalan bergantung dari usaha sendiri dan tidak mudah menyerah pada nasib atau keadaan serta tidak bergantung pada bantuan orang lain).

6. Mempunyai cara pandang positif terhadap orang lain, diri sendiri, dan situasi di luar dirinya.

7. Memiliki harapan yang realistik, sehingga ketika harapan itu tidak terwujud mampu untuk melihat sisi positif dirinya dan situasi yang terjadi.

Mengingat betapa pentingnya kemampuan komunikasi matematis dan self-confidence, sudah sewajarnya jika kemampuan tersebut dimiliki oleh siswa. Namun kenyataannya, siswa pada umumnya memiliki kemampuan komunikasi matematis, dan self-confidence yang rendah. Berdasarkan penelitian Firdaus (Nurhayati, 2014) terdapat lebih dari separuh siswa memeroleh skor kemampuan komunikasi matematis kurang dari 60\% dari skor ideal, sehingga kualitas kemampuan komunikasi matematis belum dalam kategori baik. Hal ini dikarenakan kurangnya keterlibatan siswa dalam proses belajar mengajar, sehingga pembelajaran yang cenderung berpusat pada guru menyebabkan rendahnya respon siswa terhadap pelajaran matematika. Adapun untuk aspek self-confidence, berdasarkan penelitian Zahar (Hapsari, 2011) rendahnya indeks self-confidence siswa ini jika dikaitkan dengan faktor guru disebabkan kegiatan pembelajaran yang dilaksanakan masih didominasi oleh guru dengan metode ceramah, dan menuliskan latihan soal untuk siswa di papan tulis yang 
merupakan warisan turun temurun dan dianggap paling baik. Lebih lanjut Hapsari (2011) menyatakan bahwa selama pembelajaran siswa hanya pasif mendengarkan karena tidak ada instruksi untuk melakukan suatu kegiatan selain mencatat materi dan contoh soal yang dituliskan guru. Akibatnya siswa tidak akan belajar matematika sesuai dengan kebutuhannya. Luritawati (2014: 5) juga menyatakan berdasarkan hasil pengamatan yang dilakukan di salah satu sekolah di Kabupaten Garut, hampir 80\% siswanya cenderung tidak percaya diri untuk bertanya, mengemukakan pendapat, menyelesaikan suatu permasalahan, maupun menunjukkan kemampuannya kepada siswa lain.

Berdasarkan penjelasan di atas, salah satu model pembelajaran yang dapat diterapkan untuk meningkatkan kemampuan komunikasi matematis dan self-confidence siswa adalah model pembelajaran Learning Cycle 7E. Model pembelajaran Learning Cycle $7 E$ adalah model pembelajaran yang berpusat pada siswa. Model pembelajaran Learning Cycle $7 E$ merupakan salah satu model pembelajaran dengan pendekatan konstruktivisme dan merupakan perluasan dari Learning Cycle $5 E$ yang terdiri atas lima fase yaitu engagement, exploration, explanation, elaboration, dan evaluation. Eisenkraft (2003) mengembangkan learning cycle menjadi tujuh tahapan. Perubahan yang terjadi pada tahapan siklus belajar (5E) menjadi (7E) terjadi pada fase Engagement menjadi dua tahapan yaitu Elicit dan Engagement, sedangkan pada tahap Elaboration dan Evaluaion menjadi tiga tahapan yaitu menjadi Elaboration, Evaluation dan Extend.

Tahapan model Learning Cycle 7E menurut Eisenkraft (2003) adalah sebagai berikut :

1. Elicit (memunculkan pengetahuan awal siswa), yaitu fase untuk mengetahui sampai dimana pengetahuan siswa terhadap pelajaran yang akan dipelajari dengan memberikan pertanyaanpertanyaan yang merangsang pengetahuan awal siswa agar timbul respon dari pemikiran siswa serta menimbulkan kepenasaran tentang jawaban dari pertanyaan-pertanyaan yang akan diajukan oleh guru. Fase ini dimulai dengan pertanyaan mendasar yang berhubungan dengan pelajaran yang akan dipelajari dengan mengambil contoh mudah yang diketahui siswa seperti kejadian sehari-hari secara umum memang terjadi.

2. Engagement (melibatkan), yaitu fase dimana siswa dan guru akan saling memberikan informasi dan pengalaman tentang pertanyaanpertanyaan awal tadi, memberikan siswa tentang ide dan rencana pembelajaran sekaligus memotivasi siswa agar lebih berminat untuk mempelajari konsep dan memperhatikan guru dalam mengajar. Fase ini dapat dilakukan 
dengan demonstrasi, diskusi, membaca, atau aktivitas lain yang digunakan untuk membuka pengetahuan siswa dan mengembangkan rasa keingintahuan siswa.

3. Exploration (menyelidiki), yaitu fase yang membawa siswa untuk memperoleh pengetahuan dengan pengalaman langsung yang berhubungan dengan konsep yang akan dipelajari. Siswa dapat mengobservasi, bertanya, dan menyelidiki konsep dari bahan-bahan pembelajaran yang telah disediakan sebelumnya. Pada tahap ini guru berperan sebagai fasilitator yang membantu siswa agar bekerja pada lingkup permasalahan dan memberikan kesempatan kepada siswa untuk menguji dugaan yang telah mereka tetapkan. Dengan demikian siswa diharapkan memperoleh pengetahuan dengan pengalaman langsung yang berhubungan dengan konsep yang telah dipelajari.

4. Explaination (menjelaskan), yaitu fase yang didalamnya berisi ajakan terhadap siswa untuk menjelaskan konsep-konsep dan definisi-definisi awal yang mereka dapatkan ketika fase eksplorasi. Kemudian dari definisi dan konsep yang telah ada didiskusikan sehingga pada akhirnya menuju konsep dan definisi yang lebih formal. Guru mendorong siswa untuk menjelaskan konsep-konsep dan definisi-definisi yang dipahaminya dengan kata-katanya sendiri serta menunjukkan contohcontoh yang berhubungan dengan konsep untuk melengkapi penjelasannya.

5. Elaboration (menguraikan), yaitu fase yang bertujuan untuk membawa siswa menerapkan simbol-simbol, definisi-definisi, konsep-konsep, dan keterampilan-keterampilan pada permasalahan-permasalahan yang berkaitan dengan contoh dari pelajaran yang dipelajari.

6. Evaluation (menilai), yaitu fase evaluasi dari hasil pembelajaran yang telah dilakukan. Pada fase ini dapat digunakan berbagai strategi penilaian formal dan informal. Guru diharapkan secara terus menerus dapat mengobservasi dan memperhatikan siswa terhadap kemampuan dan keterampilan untuk menilai tingkat pengetahuan dan kemampuannya, kemudian melihat perubahan pemikiran siswa terhadap pemikiran awalnya.

7. Extend (memperluas), yaitu fase yang bertujuan untuk berfikir, mencari, menemukan dan menjelaskan contoh penerapan konsep yang telah dipelajari bahkan kegiatan ini dapat merangsang siswa untuk mencari hubungan konsep yang mereka pelajari dengan konsep lain yang sudah atau belum mereka pelajari. Guru dapat mengarahkan siswa untuk memperoleh penjelasan 
alternative dengan menggunakan data atau fakta yang mereka eksplorasi dalam situasi yang baru. Selain itu, guru juga merangsang siswa untuk mencari hubungan konsep yang telah dipelajari dengan konsep lainnya.

Berdasarkan uraian di atas, maka rumusan masalah dalam penelitian ini adalah:

1. Apakah peningkatan kemampuan komunikasi matematis siswa yang mendapatkan model pembelajaran Learning-Cycle $7 E$ lebih baik daripada siswa yang mendapatkan pembelajaran konvensional?

2. Apakah self-confidence siswa yang mendapatkan model pembelajaran Learning-Cycle $7 E$ lebih lebih baik daripada siswa yang mendapatkan pembelajaran konvensional?

Sejalan dengan rumusan masalah di atas, tujuan penelitian ini adalah

1. Untuk menganalisis peningkatan kemampuan komunikasi matematis siswa yang mendapatkan model pembelajaran Learning-Cycle $7 E$ dan siswa yang mendapatkan pembelajaran konvensional?

2. Untuk menganalisis self-confidence siswa yang mendapatkan model pembelajaran Learning-Cycle $7 E$ dan siswa yang mendapatkan pembelajaran konvensional

\section{Metode}

Metode yang digunakan pada penelitian ini adalah metode kuasi eksperimen dengan mengadakan manipulasi terhadap dua kelompok. Kelompok pertama (kelas eksperimen) merupakan kelompok siswa yang mendapatkan pembelajaran dengan model Learning Cycle TE sedangkan kelompok kedua (kelas kontrol) merupakan kelompok siswa yang mendapatkan pembelajaran konvensional. Sebelum pelaksanaan pembelajaran, kedua kelas diberi pretes berupa soal-soal matematika dengan tujuan untuk mengetahui kemampuan awal siswa dalam komunikasi matematis. Setelah diberi perlakuan, siswa diberi postes untuk mengetahui kemampuan akhir dalam hal yang sama. Skor yang dihasilkan dari pretes dan postes digunakan untuk mengetahui peningkatan (gain) yang diperoleh kedua kelas. Gain yang dihasilkan dari masing-masing kelompok akan dibandingkan secara statistik.

Pretes dan postes yang diberikan pada kedua kelas menggunakan instrumen yang sama. Oleh karena itu, desain pada penelitian ini berbentuk "Pretest-Postest Control Group Design". Adapun desain penelitiannya adalah sebagai berikut:

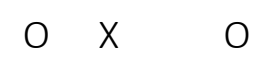

$0 \quad 0$

(Ruseffendi, 2005: 53)

Keterangan:

$\mathrm{O}=$ Pretes dan postes kemampuan komunikasi matematis

$X=$ Perlakuan terhadap kelas eksperimen berupa model pembelajaran Learning Cycle $7 E$ 
Populasi pada penelitian ini adalah seluruh siswa kelas VIII salah satu SMP di Kabupaten Garut. Sekolah yang dipilih termasuk dalam level menengah dengan pertimbangan bahwa pada level ini kemampuan akademik siswanya heterogen, sehingga dapat mewakili siswa dari tingkat tinggi, sedang, dan rendah.

Pengambilan sampel dilakukan dengan cara Purposive Sampling, yaitu teknik pengambilan sampel berdasarkan pertimbangan tertentu. Diasumsikan semua siswa mempunyai kemampuan relatif sama di setiap kelasnya karena kelas VIII disekolah tersebut tidak mempunyai kelas unggulan. Adapun untuk sampel penelitian dipilih dua kelas dari delapan kelas yang ada, yaitu kelas VIII A sebagai kelas kontrol, dan kelas VIII B sebagai kelas eksperimen.

\section{Hasil dan Pembahasan}

\section{A. Analisis Data Tes}

Hasil data yang diperoleh diolah dengan software SPSS 17 dan disajikan dalam tabel berikut:

Tabel 1.

Statistik Deskriptif Kemampuan Komunikasi Matematis Siswa Kelas Eksperimen

\begin{tabular}{|lccc|}
\hline \multirow{4}{*}{} & \multicolumn{4}{c}{ Kelas Learning } & Cycle 7E \\
\cline { 2 - 4 } \multicolumn{1}{c|}{} & $\boldsymbol{N}$ & $\overline{\boldsymbol{X}}$ & $\boldsymbol{S}$ \\
\hline Pretes & 41 & 0,268 & 0,501 \\
\hline Postes & 41 & 8,805 & 1,764 \\
\hline N-Gain & 41 & 0,727 & 0,152 \\
\hline \multicolumn{4}{c}{} \\
\hline
\end{tabular}

Tabel 2.

Statistik Deskriptif Kemampuan Komunikasi Matematis Siswa Kelas Kontrol

\begin{tabular}{|lccc|}
\hline & \multicolumn{4}{c}{ Kelas KNV } \\
\cline { 2 - 4 } \multicolumn{1}{c}{} & $\boldsymbol{N}$ & $\overline{\boldsymbol{X}}$ & $\boldsymbol{S}$ \\
\hline Pretes & 40 & 0,175 & 0,385 \\
\hline Postes & 40 & 7,125 & 1,856 \\
\hline N-Gain & 40 & 0,588 & 0,155 \\
\hline \multicolumn{4}{c}{ Skor Maksimum Ideal: 12} \\
\hline
\end{tabular}

Berdasarkan Tabel 1 dan 2 terlihat bahwa ada kenaikan kemampuan komunikasi matematis siswa setelah mendapat perlakuan. Rataan postes kelas Learning Cycle 7E sebesar 8,805 (73,375\% dari skor ideal), sedangkan rataan postes kelas KNV sebesar 7,125 (59,375\% dari skor ideal). Gambaran tersebut menunjukkan bahwa kemampuan komunikasi matematis siswa pada kelas Learning Cycle 7E lebih baik dari kelas KNV. Jika dilihat dari peningkatannya, N-gain kelas Learning Cycle 7E lebih besar dari kelas KNV, dengan kelas Learning Cycle 7E diinterpretasikan dalam kategori tinggi, dan kelas KNV dalam kategori sedang.

$\underline{\text { Uji Normalitas }}$

Tabel 3.

Data Hasil Uji Normalitas Skor Pretes Kemampuan Komunikasi Matematis Siswa

\begin{tabular}{|llccc|}
\hline \multirow{2}{*}{ Hasil } & \multicolumn{1}{c}{ Kelas } & \multicolumn{3}{c}{ Shapiro-Wilk } \\
\cline { 3 - 5 } & & Statistic & Df & Sig \\
\hline Pretes & $\begin{array}{l}\text { Learning cycle } \\
\text { 7E }\end{array}$ & 0,566 & 41 & 0,000 \\
\cline { 2 - 5 } & KNV & 0,462 & 40 & 0,000
\end{tabular}

Tabel 3 memperlihatkan hasil pretes kelas Learning cycle 7E memiliki nilai sig = $0,000<0,05$ dan kelas KNV juga memiliki nilai $\operatorname{sig}=0,000<0,05$, sehingga untuk keduanya $\mathrm{H}_{0}$ ditolak. Hal ini berarti skor pretes kemampuan komunikasi matematis 
siswa kelas Learning cycle 7E dan kelas KNV tidak berdistribusi normal. Oleh karena itu, selanjutnya pengujian hipotesis menggunakan uji nonparametrik yaitu uji Mann Whitney-U.

Uji Kesamaan Rataan Pretes Kemampua $\underline{\text { Komunikasi Matematis }}$

Tabel 4.

Data Hasil Uji Kesamaan Rataan Skor Pretes Kemampuan Komunikasi Matematis Siswa

\begin{tabular}{lc|}
\hline \multicolumn{1}{c}{ Statistik } & Nilai \\
\hline Mann Whitney-U & 760,000 \\
\hline Z & $-0,802$ \\
\hline Asymp. Sig. (2-tailed) & 0,422
\end{tabular}

Berdasarkan Tabel 4 diperoleh nilai sig. (2-tailed) $=0,422>0,05$ artinya $\mathrm{H}_{0}$ diterima. Hal ini berarti secara signifikan tidak terdapat perbedaan rataan skor pretes kemampuan komunikasi matematis siswa di kelas Learning cycle 7E dan kelas KNV.

Analisis Skor N-gain Kemampuan Komunikasi Matematis Siswa

Tabel 5.

Rataan dan Klasifikasi N-Gain Kemampuan Komunikasi Matematis Siswa

\begin{tabular}{|lll|}
\hline \multicolumn{1}{c}{ Kelas } & Rataan N-Gain & Klasifikasi \\
\hline Learning Cycle 7E & 0,727 & Tinggi \\
\hline KNV & 0,588 & Sedang \\
\hline
\end{tabular}

Tabel 6.

Data Hasil Uji Normalitas Skor N-gain Kemampuan Komunikasi Matematis Siswa

\begin{tabular}{|lllc|}
\hline \multicolumn{1}{c}{ Kelas } & \multicolumn{3}{c}{ Shapiro-Wilk } \\
\cline { 2 - 4 } \multicolumn{1}{c|}{} & Statistic & Df & Sig \\
\hline $\begin{array}{l}\text { Learning cycle } \\
\text { 7E }\end{array}$ & 0,892 & 41 & 0,001 \\
\hline KNV & 0,959 & 40 & 0,151 \\
\hline
\end{tabular}

Tabel 6 memperlihatkan bahwa N-gain kelas Learning Cycle 7E memiliki nilai sig $=$
0,001 $<0,05$ sehingga $\mathrm{H}_{0}$ ditolak. Hal ini berarti skor $\mathrm{N}$-gain kemampuan komunikasi matematis siswa kelas Learning cycle 7E tidak berdistribusi normal. Sementara itu, kelas KNV memiliki nilai $\operatorname{sig}=0,151>0,05$ sehingga $\mathrm{H}_{0}$ diterima. Hal ini berarti skor $\mathrm{N}$-gain kemampuan komunikasi matematis siswa kelas KNV berdistribusi normal. Karena salah satu data tidak berdistribusi normal, selanjutnya pengujian hipotesis menggunakan uji nonparametrik yaitu uji Mann Whitney-U.

Tabel 7.

Data Hasil Uji Kesamaan Rataan Skor N-gain Kemampuan Komunikasi Matematis Siswa

\begin{tabular}{|lc|}
\hline \multicolumn{1}{c}{ Statistik } & Nilai \\
\hline Mann Whitney-U & 418,500 \\
\hline$Z$ & $-3,824$ \\
\hline Asymp. Sig. (2-tailed) & 0,000
\end{tabular}

Berdasarkan Tabel 7 diperoleh nilai sig $=0,000$. Karena penelitian ini menggunakan uji satu pihak, sehingga nilai $\operatorname{sig}(1$-tailed $)=0,000<0,05$, artinya $\mathrm{H}_{0}$ ditolak. Hal ini berarti secara signifikan peningkatan kemampuan komunikasi matematis siswa yang mendapatkan model pembelajaran Learning Cycle 7E lebih baik daripada siswa yang mendapatkan model pembelajaran konvensional. 


\section{B. Analisis Data Non Tes}

Analisis Deskriptif Angket Self-Confidence Siswa

Tabel 8.

Deskripsi Skor Self-Confidence Siswa

\begin{tabular}{llll}
\hline \multicolumn{1}{c}{ Kelas } & Skor & $\mathbf{N}$ & $\overline{\boldsymbol{x}}$ \\
\hline C-MID & 2535 & 41 & 61,83 \\
\hline KNV & 2195 & 40 & 54,88 \\
\hline
\end{tabular}

Berdasarkan Tabel 8 dapat dilihat bahwa pencapaian rataan self-confidence siswa kelas Learning cycle 7E lebih besar dibandingkan dengan kelas KNV.

Tabel 9.

Data Hasil Interpretasi Self-Confidence Siswa

\begin{tabular}{lll|}
\hline \multicolumn{1}{l}{ Indikator } & \multicolumn{2}{c}{$\begin{array}{c}\text { Interpretasi Self- } \\
\text { Confidence Siswa }\end{array}$} \\
\cline { 2 - 3 } & \multicolumn{1}{c}{$\begin{array}{c}\text { Kelas } \\
\text { Learning } \\
\text { Cycle 7E }\end{array}$} & Kelas KNV \\
\hline $\begin{array}{l}\text { Yakin dengan } \\
\text { kemampuan yang } \\
\text { dimiliki. }\end{array}$ & Baik & Cukup \\
\hline $\begin{array}{l}\text { Bertindak mandiri } \\
\text { dalam mengambil } \\
\text { keputusan. }\end{array}$ & Cukup & Cukup \\
\hline $\begin{array}{l}\text { Selalu optimis dalam } \\
\text { menghadapi segala } \\
\text { hal. }\end{array}$ & Baik & Baik \\
\hline $\begin{array}{l}\text { Bersikap tenang dalam } \\
\text { mengerjakan sesuatu. }\end{array}$ & Baik & Cukup \\
\hline $\begin{array}{l}\text { Mampu menyesuaikan } \\
\text { diri dan komunikatif } \\
\text { dalam berbagai } \\
\text { situasi. }\end{array}$ & Baik & Cukup \\
\hline
\end{tabular}

Analisis Inferensial Angket Self-Confidence Siswa

Tabel 10.

Data Hasil Uji Perbedaan Skor Self-Confidence Siswa

\begin{tabular}{|lc|}
\hline \multicolumn{1}{c}{ Statistik } & Nilai \\
\hline Mann Whitney-U & 186,500 \\
\hline Z & $-5,998$ \\
\hline Asymp. Sig. (2-tailed) & 0,000 \\
\hline
\end{tabular}

Berdasarkan Tabel 9 diperoleh nilai sig $=0,000$. Karena penelitian ini menggunakan uji satu pihak, maka nilai sig (1-tailed $)=0,000<0,05$, artinya $\mathrm{H}_{0}$ ditolak. Hal ini berarti self-confidence siswa yang mendapatkan model pembelajaran Learning Cycle 7E secara signifikan lebih baik daripada siswa yang mendapatkan model pembelajaran konvensional.

Berdasarkan hasil analisis data di atas, kita bisa menyimpulkan bahwa model pembelajaran Learning Cycle 7E mampu meningkatkan kemampuan komunikasi matematis dan self-confidence siswa. Hal ini diantaranya dikarenakan setiap tahapan pada model pembelajaran Learning Cycle 7E mampu menciptakan suasana belajar yang memberikan ruang kepada siswa untuk belajar secara aktif dengan mengonstruksi pemahamannya sendiri, pembelajarannya dimulai dengan pengenalan masalah kontekstual, dan dalam proses pembelajarannya memberikan kesempatan siswa saling berinteraksi dalam kelompok belajar. Sehingga siswa dapat menemukan dan mengomunikasikan ide-ide yang ada pada pikirannya dan mampu mengembangkan kemandirian belajar serta kepercayaan dirinya.

\section{Penutup}

Berdasarkan hasil pengolahan data diperoleh kesimpulan bahwa peningkatan kemampuan komunikasi matematis siswa di kelas Learning Cycle 7E berada pada level tinggi, sedangkan di kelas konvensional berada pada level sedang, 
sehingga dapat disimpulkan bahwa peningkatan kemampuan komunikasi matematis siswa yang mendapatkan model pembelajaran Learning Cycle 7E lebih baik daripada siswa yang mendapatkan pembelajaran konvensional. Selain itu, self-confidence siswa yang mendapatkan model pembelajaran Learning Cycle 7E secara signifikan lebih baik daripada siswa yang mendapatkan model pembelajaran konvensional.

Hasil ini memperlihatkan bahwa model pembelajaran Learning Cycle 7E dapat digunakan sebagai salah satu model pembelajaran untuk meningkatkan kemampuan komunikasi matematis dan self-confidence siswa dalam belajar matematika. Namun karena penelitian ini hanya mengambil sampel siswa SMP, perlu dilakukan penelitian lanjutan, untuk mengetahui keefektifan model pembelajaran Learning Cycle 7E (C-MID) pada level sekolah, kemapuan kognitif dan kemampuan afektif yang berbeda. Selain itu, penelitian ini hanya mengkaji peningkatan kemampuan komunikasi matematis secara keseluruhan. Oleh karena itu, diharapkan penelitian selanjutnya dapat mengkaji peningkatan kemampuan koneksi dan matematis berdasarkan kemampuan awal siswa baik pada kategori tinggi, sedang, maupun rendah.

\section{Daftar Pustaka}

Eisenkraft, A. (2003). Expanding the 5E Model A. [Online]. Tersedia: https://www.scribd.com/document/2
89972325/7E-Model-by Eisenkraft. [5 Januari 2017].

Fatimah, E. (2006). Psikologi Perkembangan Peserta Didik. Bandung: Balai Setia.

Hannula, Markku, S., Hanna, M., \& Erkki, P. (2004). "Development of Understanding and Self-Confidence in Mathematics; Grades 5-8". Proceedings of the 28th Conference of the International Group for the Psychology of Mathematics Education vol 3 pp 17-24. [Online]. Tersedia: http://www.emis.de/proceedings/PM E28/RR/RR162 Hannula.pdf. $[10$ Januari 2017].

Hapsari, M. J. (2011). Upaya Meningkatkan Self-Confidence Siswa Dalam Pembelajaran Matematika Melalui Model Inkuiri Terbimbing. [Online]. Tersedia: http://eprints.uny.ac.id/7385/1/p30.pdf. [1 Februari 2017].

Izzati, N \& Suryadi, D. (2008). Komunikasi Matematik dan Pendidikan Matematika Realistik. Prosiding Seminar Nasional Matematika dan Pendidikan Matematika, Yogyakarta, UNY, 27 Nov 2010, ISBN : 978-97916353-5-6

Lazard, S., Suzzane, M., dan Lee, Y. P. (2011). "Strong Links between SelfConfidence and Math Performance". Singteach.nie.edu.sg issue $29 \mathrm{Mar} / \mathrm{Apr}$ 2011. [Online]. Tersedia: http://singteach.nie.edu. sg/issue29mathed/. [08 Februari 2017]. 
Luritawati, I. P. (2014). Meningkatkan Kemampuan Penalaran Matematis dan Self-Confidence Siswa melalui Model Pembelajaran Think-Talk-Write (TTW). Tesis. SPs UPI Bandung: tidak diterbitkan.

Nurhayati, N. (2014). Pengaruh Pembelajaran dengan pendekatan Reciprocal Teaching terhadap Peningkatan Kemampuan Komunikasi dan Disposisi Matematis Siiswa SMP. Tesis. SPs UPI Bandung: tidak diterbitkan

Pugalee, D. A. (2001). Using Communication to Develop Students Mathematical Literacy. Journal Mathematics Teaching in the Middle School, 6(5). 269-299. [Online]. Tersedia:

http://www.google.com/url?sa=t\&rct $=\quad j \& q=\& e s r c$

$=s \&$ source $=$ web $\& c d=3 \&$ ved

=0CDAQFjAC\&url=http\%3A\%2F\%2Fw ww .nctm. org\% 2Fupl oaded Files\%2FProfessional_Development\% 2 Fenhanc ed_Articles\%2FMTMS\% 2520 Communication.pdf\&ei=XDK_ VorY A 4vi8AX 44oGQBw\&usg=AFQjCNFn8BNxsZZ46 EyxDYcz1InKv7zFAQ

\&bvm=bv.83829542,d.dGc.
Ruseffendi, H. E. T. (2005). Dasar-dasar Penelitian Pendidikan dan Bidang Non Eksakta Lainnya. Bandung: Tarsito.

Saragih, S. (2007). Mengembangkan Kemampuan Berpikir Logis dan Komunikasi Matematik Siswa Sekolah Menengah Pertama Melalui Pendekatan Matematika Realistik. Disertasi UPI Bandung: Tidak Diterbitkan.

Sudrajat, Akhmad. (2008). Pengertian Pendekatan, Strategi, Metode, Teknik, Taktik, dan Model Pembelajaran. [Online]. Tersedia: http://akhmadsudrajat.wordpress.co $\mathrm{m} / 2008 / 09 / 12 /$ pendekatan-strategi metode-teknik-dan-modelpembelajaran. [30 Januari 2017].

Sumarmo, U. (2013). Kumpulan Makalah Berpikir dan Disposisi Matematik serta Pembelajarannya. Bandung: FMIPA UPI

Sutisna. (2010). Peningkatan Kepercayaan Diri Siswa Melalui Strategi Layanan Bimbingan dan Kelompok. Tesis.SPs UPI Bandung: tidak diterbitkan.

Turmudi. (2008). Landasan Filsafat dan Teori Pembelajaran Matematika (Berparadigma Eksploratif dan Investigatif). Jakarta: Leuser Cita Pustaka. 
This page is intentionally left blank 